\title{
A Rare Case of Angiofibroma Mimicking Fibrous Epulis in Posterior Gingival Mucosa
}

\author{
Annete Nabila, DDS, ${ }^{1}$ Ni Putu Mira Sumarta, DMD, PhD ${ }^{1}$ and Okky Prasetio, DMD² \\ ${ }^{1}$ Department of Oral and Maxillofacial Surgery, Faculty of Dental Medicine, Universitas Airlangga, Surabaya, Indonesia \\ ${ }^{2}$ Department of Oral and Maxillofacial Surgery, Dr. Mohammad Soewandhie General Hospital, Surabaya, Indonesia
}

\begin{abstract}
Angiofibromas are highly vascular, locally aggressive but histologically benign tumors. A 40-year-old woman complaint of pedunculated mass in the right gingiva of the posterior region since 7 months earlier. Surgical excisional biopsy under general anesthesia was performed. Histopathological examination showed an angiofibroma. Angiofibromas are localized in the superficial soft tissue and the gingiva could have a similar clinical appearance as an epulis. Definitive diagnosis was determined through histopathological analysis.
\end{abstract}

Key Words: Angiofibroma, Fibrous Epulis, Gingival Angiofibroma, Gingival Mucosa

\section{INTRODUCTION}

Angiofibromas are highly vascular, locally aggressive but histologically benign tumors. ${ }^{1}$ In the head and neck region, angiofibromas are most frequently seen in the nasopharynx of male patients aged 7-25 years old with the incidence varying between 0.05 and $0.5 \% .^{2}$ Extra nasopharyngeal localization of this tumor is rare. The pathogenesis of angiofibroma is not very clear. These mesenchymal tumors can appear as a result of infection, trauma, hormones, and arteriovenous malformation. ${ }^{3}$

Diagnosing could be a challenge due to a wide spectrum of various mesenchymal tumors reported in the literature with similar clinical and histological features. This may cause relevant problems with the differential diagnosis because of the tumor's rarity, ambiguous clinical presentation, and histologic features. A definitive diagnosis can be determined through histopathological analysis.

The purpose of this case is to report a case of angiofibroma mimicking fibrous epulis in posterior gingival mucosa. We report an interesting and rare case of angiofibroma involving posterior gingival mucosa treated by surgical excision in a 40-year-old female patient.

\section{CASE REPORT}

Paper presented in the Temu IImiah Nasional-Internasional ke-8 (TIMNASS 8).

Corresponding author: Ni Putu Mira Sumarta, DMD, PhD Department of Oral and Maxillofacial Surgery

Faculty of Dental Medicine

Universitas Airlangga

Surabaya, Indonesia

Email: niputu.mira@fkg.unair.ac.id

niputumira.fkgunair@gmail.com

A 40-year-old woman presented in the Oral and Maxillofacial Clinic of Dr. Mohammad Soewandhie General Hospital, Surabaya, Indonesia with a chief complaint of a pedunculated mass in the lower right gingiva of the posterior region in the past 7 months earlier. In the beginning, it was similar to stomatitis with a red and white color pattern, then it grew larger over the past 5 months. There was no sharp tooth edge or filling. Extraoral examination 

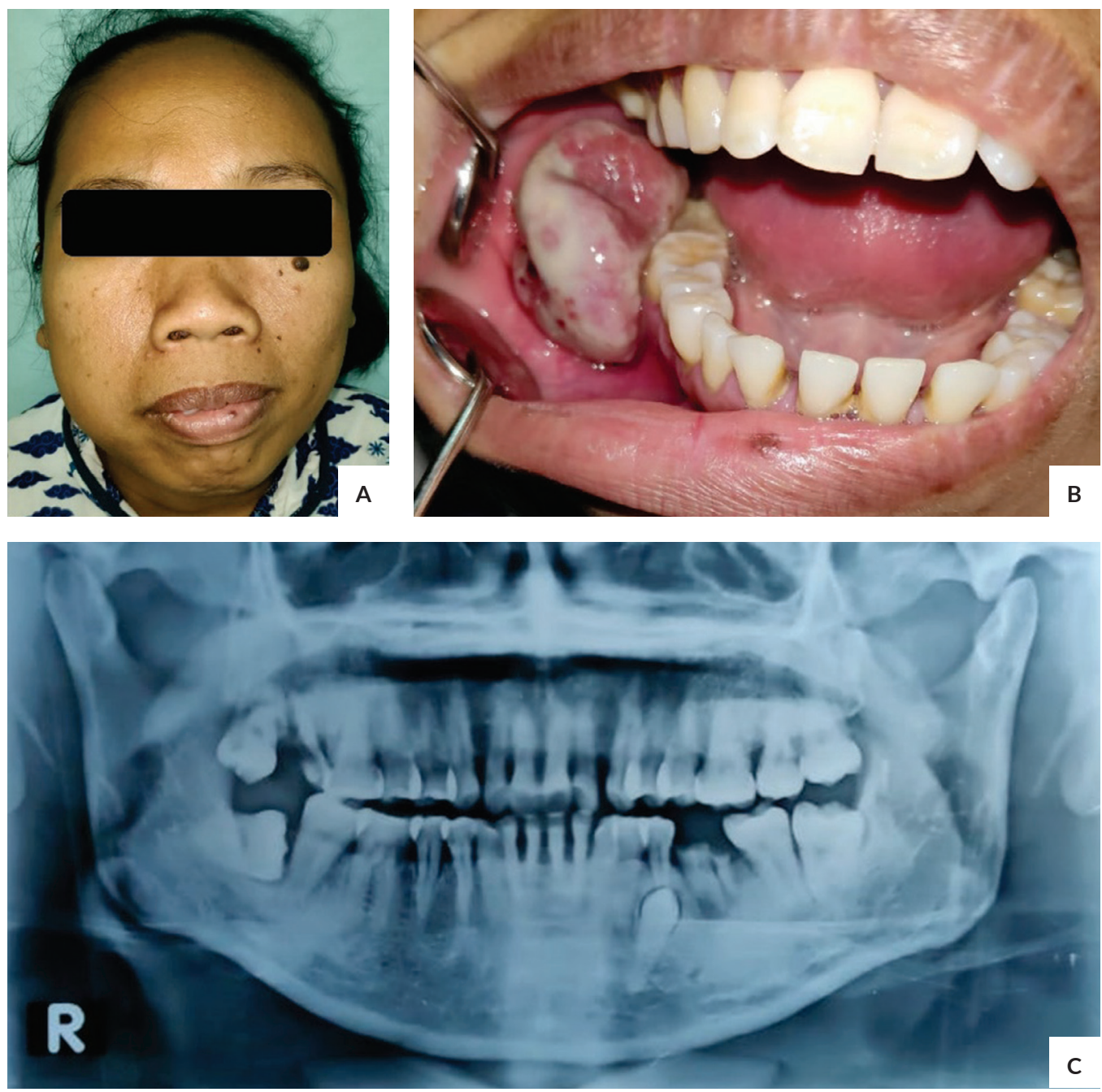

Figure 1. (A) Extraoral clinical view showed an asymmetrical face. (B) The intraoral clinical view showed a pedunculated mass in the right lower gingiva mucosa of the first and second molars region measuring approximately $3 \times 2 \times 1 \mathrm{~cm}$. (C) Panoramic radiograph showed vertical resorption on the alveolar crest on the first and second molar of the right mandible.

showed an asymmetrical face. The overlying skin was normal in color and texture (Figure 1A). Upon palpation, there was a mass on the right side of the mandible with diffuse border and average consistency with no tenderness.

Intraoral examination revealed a pedunculated mass on the right lower gingival mucosa of the first and second molars region measuring about $3 \times 2 \times 1 \mathrm{~cm}$ (Figure 1B). It was lobulated, showing red and white color pattern covered with a white membrane in some parts of the lesion. Upon palpation, the mass was solid, bled easily, with average consistency, smooth surface, with no tenderness. The first and second molars were mobile. On panoramic view, there was vertical resorption on the alveolar crest of the first and second molars of the right mandible with widened periodontal space (Figure 1C).

Clinical diagnosis of fibrous epulis was made and was confirmed based on cytological analysis using fine-needle aspiration biopsy. A surgical excisional biopsy was performed under general anesthesia. The mass was ligated from the shaft then excised along with surgical removal of the right mandibular first, second, and third molars (Figure 2). Massive bleeding occurred while removing the mass which was controlled by using electrocautery. The periosteum and periodontal ligament area was then curettage, then sutured with vicryl 4.0. The healing was eventful. The patient was followed up until 4 months with no complaint (Figure 3).

The specimen was submitted for histopathologic analysis. Histopathology revealed a section of tissue covered with stratified squamous epithelium lining (Figure 4). The stroma consists of vascular proliferation with endothelial lining with erythrocytes within its lumen and fibrous cell proliferation with myxomatous degeneration. It was concluded as angiofibroma of the gingiva. 


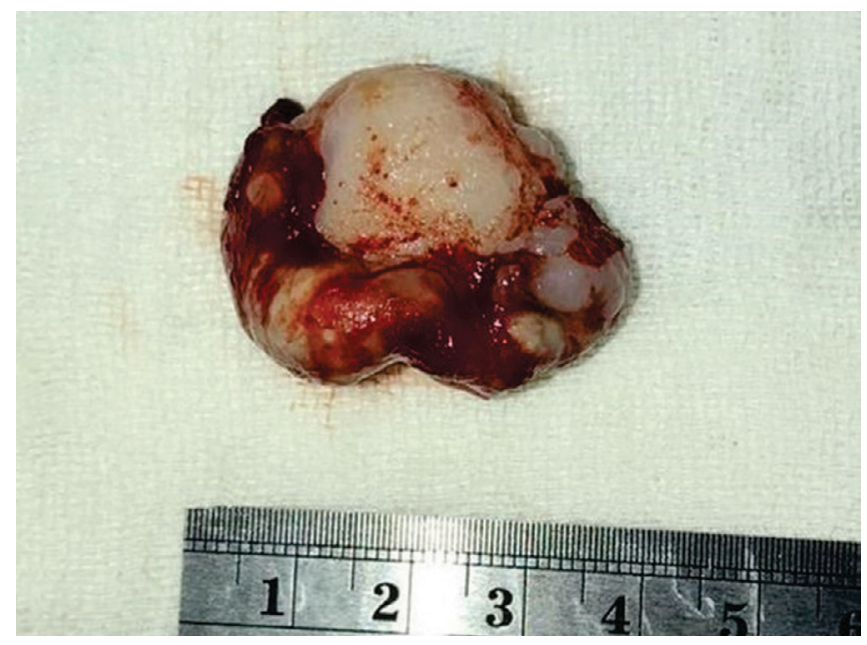

Figure 2. Excised specimen measuring about $3.5 \times 3 \times 2.5 \mathrm{~cm}$ with red and white color pattern.

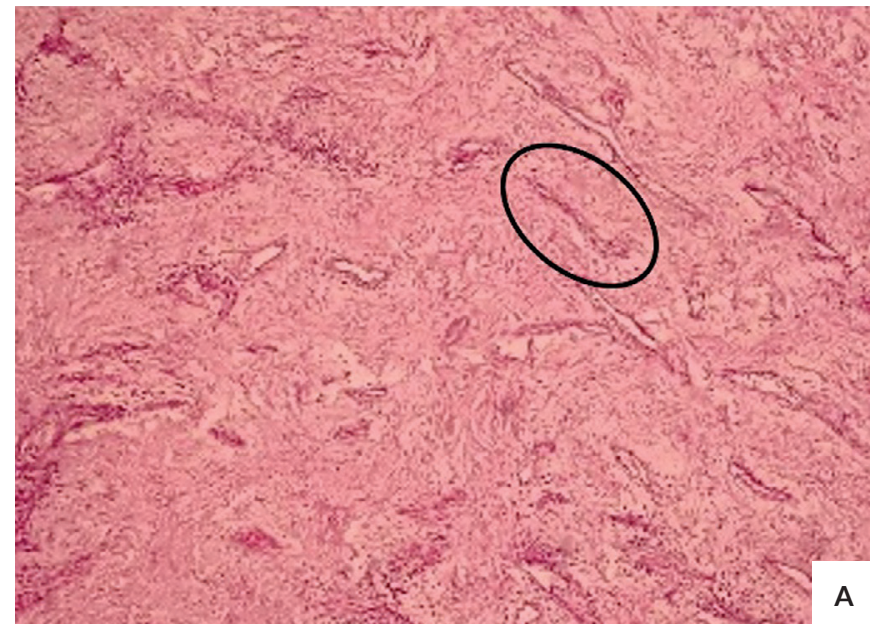

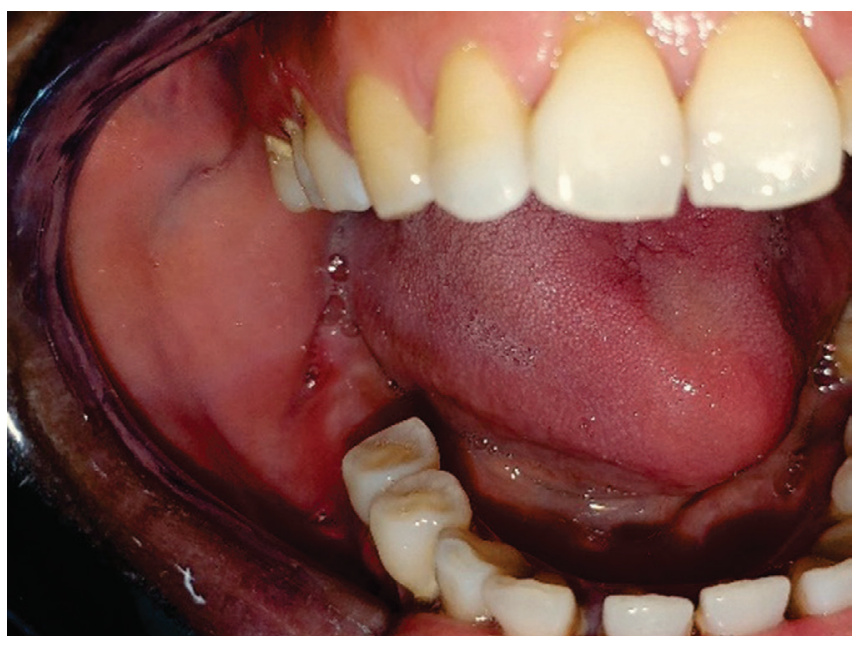

Figure 3. Post-operative view after four months.

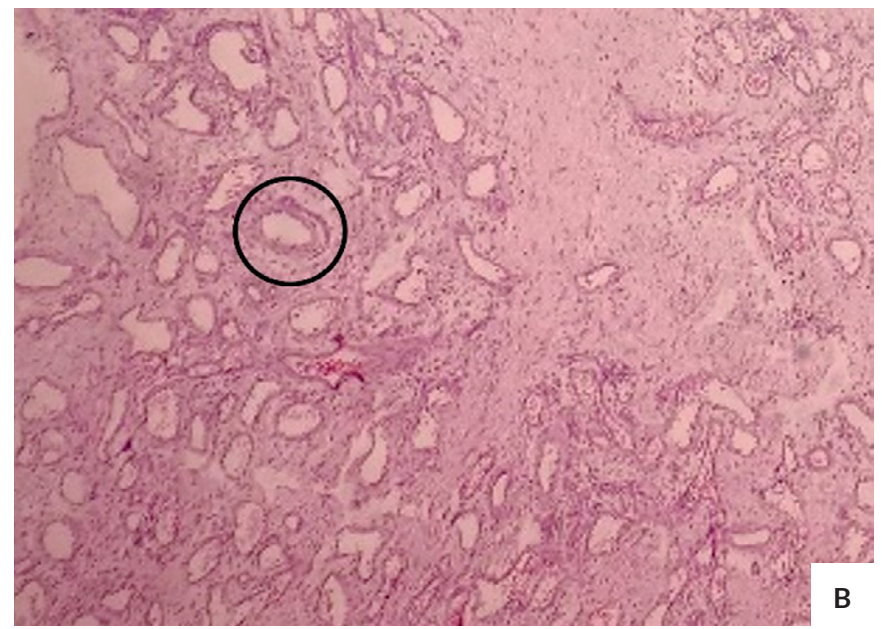

Figure 4. (A) Histopathologic view of fibrous cell proliferation (the oval area) (HE 100x). (B) Histopathologic view of vascular proliferation (the circled area) (HE 400x).

\section{DISCUSSION}

Epulis is a relatively frequent benign lesion in the oral cavity. ${ }^{4}$ It may occur at any age but it is most commonly found in patients in their twenties and sixties, and more frequently in women than men. ${ }^{5}$ There are four types of epulis, depending on the prevalent histological component: fibrous, granulomatous (pyogenic granuloma), angiomatous and giant cells epulis. According to several authors, they correspond to different developing stages of a single pathological entity that, at the initial stages, would be rich with vascular and cellular components while the fibrous constituent progressively increases over time. ${ }^{4}$

Fibrous epulis is considered to be one of the most common benign growth occurring on the gingiva. ${ }^{4}$ The most common clinical aspect of the fibrous epulis is the growth of well-delimited tissue, of a smooth surface, usually with normal colored mucosa, with a sessile or pedunculated base of hard consistency in the interdental papilla. ${ }^{6}$

There was another lesion in the gingiva which is a neoplastic lesion called angiofibroma while fibrous epulis is hyperplastic, but both lesions could cause by infection. Angiofibroma is a relatively rare tumor. Only a few cases have been reported in the maxillofacial complex in females. ${ }^{7}$ Angiofibromas are commonly well-circumscribed tumors, localized in the superficial soft tissue and characterized by bland spindle-shaped cells arranged within vessels. The diagnosis of angiofibroma is dependent more on histological confirmation due to its close resemblance with other lesions. ${ }^{1}$

Despite the clinical similarities between the angiofibroma presented in this study and fibrous epulis, both lesions could be differentiated through their histopathological picture although the pathogenesis could be similar. Fibrous 
epulis consists of a predominantly hyperplastic stratified squamous epithelium and consists of connective tissue characterized by variable collagen deposition and variable chronic inflammatory infiltration depending on the stage of development. ${ }^{8}$ Angiofibroma consists essentially of two basic and characteristic components: a vascular network and a connective tissue stroma. The vessels comprising the vascular network are of varying caliber, irregular in shape, and generally consisting of a simple endothelial lining. The connective tissue stroma consists of both fine and coarse collagen fibrils. An abundance of mast cells in the stroma and a lack of other inflammatory cells exists. Hyalinized foci are sometimes present, as well as areas resembling myxomatous degeneration. ${ }^{9}$

The histopathological picture described, in our case, was lined with squamous epithelium. The stroma consists of vascular proliferation with endothelial lining with erythrocyte within its lumen and fibrous cell proliferation with myxomatous degeneration. This showed the basic and characteristic of angiofibroma which was a vascular network and a connective tissue stroma. These characteristics could not be found in fibrous epulis.

This case was the first angiofibroma found in the Oral and Maxillofacial Clinic of Dr. Mohammad Soewandhie General Hospital, Surabaya, Indonesia since 2015. This showed the rareness of angiofibroma. On intraoral examination, during the palpation, the mass bled easily which matched the highly vascular character. The authors proposed that chronic infection might be to be the etiology of this case based on anamnesis and clinical examination.

The treatment of choice for angiofibroma and fibrous epulis is surgical excision. The treatment in this case including the extraction of the neighboring teeth considering there was underlying bony involvement. The first and second molars were mobile and there was vertical resorption on the alveolar crest of the first molar and second molars of the right mandible. Massive bleeding occurred while removing the giant mass. It was controlled by using electrocautery. Curettage of the periosteum and periodontal ligament cells area was performed to prevent a recurrence. Thakur et al. reported an angiofibroma case that was excised from the base of the peduncle using a diode laser due to superior hemostasis and no sutures were required. ${ }^{1}$ Mahmood et al. reported the pedicle had been completely transected with bipolar diathermy, with insignificant bleeding which was controlled with electrocautery. ${ }^{10}$

The recurrence rate of angiofibroma varies in some series. Sun et al. reported the recurrence occurred in $21.7 \%$ of the patients with tumor size less than $4 \mathrm{~cm}$ and $54.9 \%$ of the patients with tumor size more than $4 \mathrm{~cm} .{ }^{11}$ Gaillard et al. reported a recurrence rate of $43.75 \%$ and the relapse time after surgery ranged from 1 month to 3 years. ${ }^{12}$ The recurrence rate of fibrous epulis ranges from 8 to $16 \% .^{13}$ Angiofibroma has a higher recurrence rate than fibrous epulis.

\section{CONCLUSION}

Angiofibroma of the oral cavity can resemble an epulis. Treatment of choice for angiofibroma and fibrous epulis is by surgical excision. Curettage of the area was done from the periosteum and periodontal ligament cells to prevent recurrences.

\section{Acknowledgment}

The authors thank the Faculty of Dental Medicine, Universitas Airlangga and Dr. Mohammad Soewandhie General Hospital, Surabaya, Indonesia.

\section{Statement of Authorship}

All authors participated in the data collection and analysis and approved the final version submitted.

\section{Author Disclosure}

All authors declared no conflicts of interest.

\section{Funding Source}

None.

\section{REFERENCES}

1. Thakur RK, Madan E, Tomar A, Arora M. (2014). Angiofibroma on Cheek Mucosa: A Rare Entity and its Management with Laser. Journal of Cutaneous and Aesthetic Surgery, vol. 7, no. 4, pp. 227-9.

2. Celik B, Erisen L, Saraydaroglu O, Coskun H. (2005). Atypical angiofibromas: a report of four cases. International Journal of Pediatric Otorhinolaryngology, vol. 69, no. 3, pp. 415-21.

3. Bokhari K, Luqman M, Muhammed A, Mohammad S, Mustafa AB, Zaheer K. (2012). Cellular angiofibroma of the buccal mucosa: A rare case report and review of literature. International Journal of Experimental Dental Science, vol. 1, no. 1, pp. 23-5.

4. Laus M, Conti MA, Croce A. (2016). Giant Fibrous Epulis: A Case Report of a Benign Mass of the Oral Cavity. International Journal of Otorhinolaryngology and Head and Neck Surgery, pp. 228-32.

5. Khzam N, Shah Mansouri R, Poli A, Bakr MM. (2017). Fibrous epulis misdiagnosed for combined periodontic-endodontic lesion. International Journal of Medical and Dental Sciences, pp. 1546-52.

6. Jadhav PM, Khale PA, Premchandran R. (2015). Fibrous Gingival Epulis: A Case Report Of A One Year Old Lesion. International Journal of Current Research, vol. 7, no. 9, pp. 20148-52.

7. U1 Khaliq MI, Shah AA, Dar N. (2016). A rare case of angiofibroma of the mandible: A case report. Journal of Oral Biology and Craniofacial Research, vol. 6, no. 2, pp. 168-70.

8. Fonseca GM, Fonseca RM, Cantín M. (2014). Massive fibrous epulis-a case report of a 10-year-old lesion. International Journal of Oral Science, vol. 6, no. 3, pp. 182-4.

9. Shafer AW, Hine MK, Levy BM. (2015). Shafer's Textbook of Oral Pathology 7th Edition. New Delhi: Elsevier.

10. Mahmood AN, Sheikh R, Saey HA, Ashkanani S, Ganesan S. (2016). Angiofibroma Originating outside the Nasopharynx: A Management Dilemma. Case Reports in Otolaryngology, Article ID 3065657

11. Sun XC, Wang DH, Yu HP, Wang F, Wang W, Jiang JJ. (2010). Analysis of risk factors associated with recurrence of nasopharyngeal angiofibroma. Journal of Otolaryngology - Head \& Neck Surgery, vol. 39 , no. 1 , pp. 56-61.

12. Gaillard AL, Anastácio VM, Piatto VB, Maniglia JV, Molina FD. (2010). A seven-year experience with patients with juvenile nasopharyngeal angiofibroma. Brazilian Journal of Otorhinolaryngology, vol. 76, no. 2, pp. $245-50$.

13. Neville BW, Damm DD, Allen CM, Chi AC. (2015). Oral and Maxillofacial Pathology 4th Edition. Missouri: Saunders Elsevier. 